\title{
Ectopic Eyelid Cilia in a 15 years old Girl: A Rare Presentation
}

\author{
Manita Sunam Godar, ${ }^{\mathrm{a}, \mathrm{d}}$ Ruchi Shrestha, ${ }^{\mathrm{b}, \mathrm{e}}$ Krishna Chandra Godar ${ }^{\mathrm{c}, \mathrm{f}}$
}

\begin{abstract}
:
Introduction: Eyelashes are unique hair follicles normally found at the eyelid margin. The spectrum of cilial anomalies includes cilial row duplication, agenesis and ectopic placement. Ectopic cilia are the rarest of cilial anomalies.

Case Report: A 15 years old girl presented with the complaints of eyeache and headache for three months. She also complained of extra lashes over left upper eyelid with secretion of tears while crying from the area of extra lashes. She was a diagnosed case of epilepsy under treatment for three months.

On examination, visual acuity was $6 / 6 \mathrm{p}$ in right eye and 6/6p in left eye with best corrected visual acuity being 6/6 with $-0.25 \mathrm{DS}$ in both the eyes. The anterior and posterior segment findings were normal except for presence of extra bunch of cilia on the temporal side of the left upper eyelid two $\mathrm{mm}$ above the upper lid crease with dimpling of the underlying skin.

Conclusion: Ectopic cilia, a rare congenital condition, is asymptomatic and surgical treatment can be done for cosmetic correction.
\end{abstract}

Keywords: cilia, ectopic, eyelid

\section{INTRODUCTION:}

Ectopic cilia, a rare entity, are the congenital disturbance of the position of the eyelashes, usually on the lateral quadrant of the upper eyelid or conjunctival surface of the eyelid. The origin is not clear. The theory of meibomian gland substitution has been refuted and an embryologic origin suggested. In most cases, it causes no apparent medical morbidity and there is no positive family history. Treatment is surgical excision, mostly for cosmetic reasons. [1] No case of ectopic eyelid cilia has been reported till date from Nepal.

\section{CASE REPORT:}

A 15 years old girl presented with the complaints of eyeache and headache for three

Submitted: 12 July, 2018, Accepted: 02 October, 2018

Published: 26 October, 2018

a - Assistant Professor, Ophthalmologist b - Ophthalmologist

c - Lecturer

d - Lumbini Eye Institute, Bhairahawa, Rupandehi, Nepal

e - Reiyukai Eiko Masunaga Eye Hospital, Banepa, Nepal

f - Lumbini Medical College Teaching Hospital, Palpa, Nepal

\section{Corresponding Author:}

Manita Sunam Godar, e-mail: manitagodar@gmail.com

ORCID: https://orcid.org/0000-0003-0883-132X

How to cite this article:

Godar MS, Shrestha R, Godar KC. Ectopic Eyelid in a 15 years old girl: A Rare Presentation. Journal of Lumbini Medical College. 2018;6(2):2 pages. DOI: https://doi.org/10.22502/jlmc.v6i2.166 Epub:2018 October 26. months. She also complained of extra lashes over left upper eyelid with secretion of tears while crying from the area of extra lashes since birth. She was a diagnosed case of epilepsy under treatment for three months. Her birth history was uneventful. There was no history of systemic dermatologic condition. On examination, visual acuity (VA) was $6 / 6 \mathrm{p}$ in right eye and $6 / 6 \mathrm{p}$ in left eye with best corrected visual acuity (BCVA) being $6 / 6$ with $-0.25 \mathrm{DS}$ in both the eyes. Slit lamp biomicroscopy of the anterior segment was normal and the dilated fundus examination with $+90 \mathrm{D}$ lens revealed the normal posterior segment findings. The upper eyelid of the left side had extra bunch of cilia on the temporal side two $\mathrm{mm}$ above the upper lid crease with dimpling of the underlying skin. There was no tenderness. There was no discharge on compression. Lid eversion showed the normal tarsal conjunctiva with no such anomaly.

The patient was comfortable with the condition and did not want to undergo surgical excision.

\section{DISCUSSION:}

Congenital ectopic cilia of the eyelid, a rare entity, have been observed to protrude from the anterior surface of the eyelid skin and the posterior aspect of the tarsal plate. All anterior examples of ectopic cilia have been located in the lateral aspect of the upper eyelid.[2] The first reported case of ectopic cilia was described in 1936 by Weigmann in 
a patient who had aberrant cilia emanating from the palpebral conjunctiva.

It is typically an isolated congenital finding in otherwise healthy children without a known family history. However, Baquestani reported a case with positive family history demonstrating evidence of an inherited genetic disorder.[3] Cordon et al. reported a complex choristoma containing ectopic cilia and functioning aberrant lacrimal gland tissue, intermittently producing tears.[4]

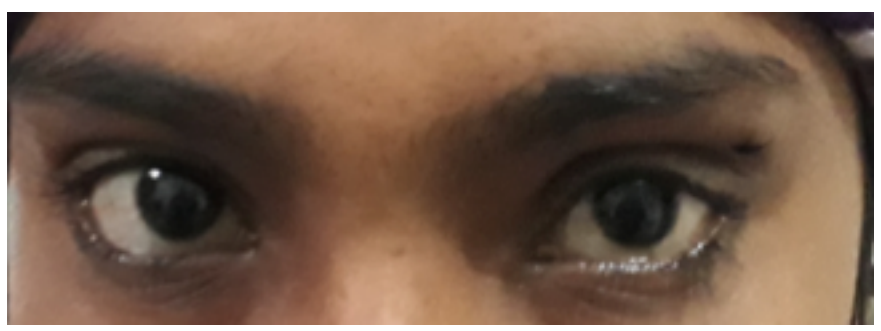

Fig 1. Ectopic cilia on left upper lid in primary gaze

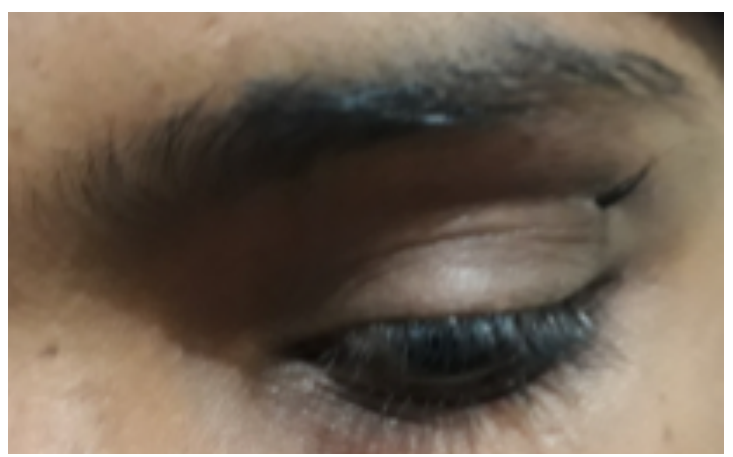

Fig 2. Ectopic cilia on left upper eyelid on down gaze

Histologic examination of the specimens demonstrated the presence of apocrine and pilosebaceous glands.[5] Ectopic cilia adherent to the underlying tarsus during surgical excision have been reported.[6]

No satisfactory explanation has been proposed to account for the development of congenital ectopic foci of cilia. Some authors have postulated that these lesions arise in an area of the eyelid in which the normal mesodermal tissue is absent or as a result of a vascular accident.[5, 6]

Recently MacQuillen et al.[6] and Chen et al.,[5] have proposed that the anomaly is likely due to inappropriate differentiation during embryogenesis, given its congenital presentation and its predilection for the lateral portion of the upper eyelid as in our case.

Similar to our case the onset of copious tearing triggered by environmental irritants that arose from the base of several ectopic cilia had been described in an 8-year-old boy by McCulley et al[7] and in a 19 years old girl by Micheal et al.[2] The presence of sebaceous and apocrine glands in the ectopic cilia and the absence of lacrimal acini or ducts suggest that the secretion from the aberrant cilia is not derived from the lacrimal gland and is not tear. Instead, the moisture represents a mixture of the by products of sebaceous and apocrine glands.[2]

The preferred treatment for ectopic cilia is surgical excision. One case has been reported for recurrence that may have been due to incomplete excision.[8]

\section{CONCLUSION:}

Ectopic cilia, a rare congenital condition, is usually asymptomatic. Surgical excision is the treatment for cosmetic correction.

\section{Acknowledgement:}

Rima Verma, Dr. Binod Neeta Kandel, Eye Hospital, Parasi

\section{Conflict of interest:}

None declared.

\section{REFERENCES:}

1. Fabricio L da Fonseca,Patricia K Yamanaka, Patricia $P$ Lima, Suzana Matayoshi. A 6 years old girl with ectopic cilia and hypochromic nevus. Clin Ophthalmol 2014; 8: 1256-1261. DOI: 10.2147/OPTH.S63313

2. Michael C. Chappell, William Spencer,Susan H. Day,Rona Z. Silkiss. Congenital Ectopic Cilia of theUpper Eyelid. Ophthal Plast Reconstr Surg 2011; 27(2):42-44. DOI: 10.1097/IOP.0b013e3181e17501

3. Baghestani S, Banihashemi SA. Ectopic cilia in a 14year-old boy.Pediatr Dermatol. 2011 Jan-Feb; 28(1):55-6. PMID:21276055 DOI:10.1111/j.1525-1470.2010.01354.X

4. Cordon AJ, Patrinely JR, Knupp JA, Font RL. Complex choristoma of the eyelid containing ectopic cilia and lacrimal gland.Ophthalmology.1991; 98:1547-1550. DOI: $10.1016 / \mathrm{S} 0161-6420(91) 32090-6$

5. Chen TS, Mathes EF, Gilliam AE. Ectopic eyelashes (ectopic cilia) in a 2-year-old girl: brief report and discussion of possible embryologic origin. J Pediatr Dermatol. 2007; 4(4):433-5. PMID:17845181 DOI: $10.1111 / \mathrm{j} .1525-1470.2007 .00473 . \mathrm{x}$

6. MacQuillan A, Hamilton S, Grobbelarr A. Angiosomes, clefts, and eyelashes. Plast Reconstr Surg. 2004; 113:1400 -3. DOI: 10.1097/01.PRS.0000112793.45806.7A

7. McCulley TJ, Yip CC, Kersten RC, Kulwin DR. An ectopic site of lacrimal gland secretion mimicking epiphora.Arch Ophthalmol.2002; 120:1586-7. [Publisher Full Text]

8. Tanuj Nakra, Sean M. Blaydon,Vikram D. Durairaj, Roman Shinder. Congenital Upper Eyelid Ectopic Cilia. Pediatr Ophthalmol Strabismus 2011; 48:16-18. DOI: 10.3928/01913913-20110208-08 